\title{
The effects of online shopping on the customer loyalty
}

\author{
Hamideh Afrashteh, Naser Azad and Seyed Vali Tabatabaei Hanzayy*
}

Department of Management and Accounting, South Tehran Branch, Islamic Azad University, Tehran, Iran

\begin{tabular}{|c|c|}
\hline CH R O N I C LE & A B S T RACT \\
\hline $\begin{array}{l}\text { Article history: } \\
\text { Received January 20, } 2014 \\
\text { Accepted } 5 \text { July 2014 } \\
\text { Available online } \\
\text { August } 102014 \\
\text { Keywords: } \\
\text { Online shopping } \\
\text { E-commerce } \\
\text { Customer loyalty }\end{array}$ & $\begin{array}{l}\text { This paper investigates the use of Online Shopping as one of electronic marketing techniques as } \\
\text { well as the effect of applying this shopping method and marketing on customer loyalty in Iran. } \\
\text { The variables are extracted according to the review of literature and studies conducted in the } \\
\text { field of shopping through cyberspace. A questionnaire is designed by applying these variables } \\
\text { and distributed among a sample of service providers and users after testing its reliability and } \\
\text { validity. Performing the statistical tests on the results of investigation led to the identification } \\
\text { of effective factors. In addition, another questionnaire is distributed according to the obtained } \\
\text { components in order to achieve a structural model for the impact of components on the } \\
\text { customer loyalty. The structural equation modeling (SEM) is designed to learn the impact of } \\
\text { obtained components on customer loyalty as a basis influencing on the survival of business } \\
\text { space using SEM method. The study identified different components affected by utilization of } \\
\text { online shopping websites including comprehensive information system, system development, } \\
\text { choice power, viability and system optimization. }\end{array}$ \\
\hline
\end{tabular}

\section{Introduction}

In today's world and while facing with huge volumes of electronic transactions, the e-commerce is as an inalienable part of electronic world. The investment, electronic marketing, electronic payments, online stores, auction markets, etc., the whole ones contain the only corner of vast electronic commerce. Nowadays, many large stores easily sell their products via the Internet, and firms improve their enormous exchanges on the Internet. The e-commerce branches have been considered pervasive today and many firms are working at the international level. On the other hand, due to the richness of human culture and knowledge and the unprecedented growth of technology in modern and industrial societies, the producers have paid special attention to customer loyalty, satisfaction, trust and their emotional and mental security as well as the health and quality of target product or service in production and supply of services. The increased competition in the supply of goods and services is what attracts the producers to the demanders' interests and demands. Undoubtedly, it can be achieved

*Corresponding author.

E-mail addresses: farnooshtaherkhani@yahoo.com (S. V. Tabatabaei Hanzayy) 
in Iran through changing from the selling oil revenue as the mono-product economy, as well as utilization of new knowledge, and development of non-oil exports through using the new spaces such as cyberspace and electronic world. The presence in the global markets and the persistence in its evolving and diverse situations need to be consistence with the accelerated scientific-technological development. Furthermore, the international markets belong to the countries, which can manage the market in line with scientific findings and technological achievements and increased data transfer speed. Unfortunately, one of the challenges is the lack of such these spaces to provide online services for customers. In Iran, the state enterprises generally provide their services via the web for the public and the private enterprises have failed to be properly successful in this regard. There are almost a few numbers of online Iranian stores proportional to the international standards according to the population of this country and most of these stores generally fail at the beginning of their career or have no growing development due to the customers' very low interest. Customers do generally not welcome most of these websites and this may have roots in the tradition-oriented culture of the public, who are not interested in using new methods for purchase, or the inability of enterprise to satisfy customer while purchasing. Therefore, investigating the factors influencing the online shopping websites and evaluating the impact on the customer loyalty can have positive effects on the customer loyalty and survival of enterprise and making it profitable in order to improve the quality of service and focus on mentioned factors. The development of the Internet and its utilization by all classes of society in various countries around the world create this opportunity to change the structure of e-commerce from being exclusive to a certain class to a phenomenon for all people. There have been serious investigations of e-commerce and the practical procedures for its implementation in Iran. Due to its importance and wide applications including the use of web-based shopping and providing the online services, which are more necessary in current society, they are led to the profit for the enterprise and made the Iranian society technological and thus will create the fundamental changes in the Iranians' culture and lifestyles.

\section{Theoretical backgrounds}

\subsection{Impressive features of websites}

The websites' features and advantages, which have improved the conditions of current trading, can be assessed in a set for examining the impact of each one on the customer loyalty. The structure forming the websites is a set of client-side codes such as HTML codes and server-side codes, multimedia systems, graphic files, high vivid images as mentioned in "Creating emotions via B2C websites" and each one influence the aesthetics and customer decisions. Through the collage effect of these media, websites often remediate the newspapers or journals (Jones et al., 2008). Another point is the capability of storing the search spaces and settings, which are generally welcomed by clients and customers. As the result of buyers' reduced search costs, the price-based competition is increased, it becomes easier for buyers to extensively search market for better deal before purchase, and it can decrease the sellers' margins. Thus, the enhanced price-based competition can explain the reason why fewer firms develop the commercial websites. In fact, if we want to make a comparison with traditional sales, the conditions of storing the goods and visited places are provided for purchase in online shopping and it can be investigated as an option, which may be welcomed by the majority of consumers in Iran. The selection factor can be defined as the ability to give purchasers the online access to pricing and other information which allow them to compare various offerings and choose a supplier for the target input (Al-Khalifa \& Al-Khalifa, 2012).

\subsection{E-commerce Quality test}

According to Zalatar (2012), the quality of e-commerce should be evaluated in terms of 15 dimensions and in fact the components and qualitative evaluation of a web site can include the performance, aesthetics, reliability, storage capacity, security and integrity of system, trust, level of 
responsiveness Product/Service Differentiation and Customization, and the empathy utilized in this test (Al-Khalifa \& Al-Khalifa, 2012).

\subsection{Investigating the Quality of C2C on Online Shopping Websites}

The possibility of online conversation, which significantly differs from other forms of media such as radio and television, etc. is among the features offered on websites and each one may have a major influence on customers' decision making and loyalty to the website. Two-way communication makes the customer as an agent to generate information and also using the chat rooms, Email, and making the comments on social networking are all the spaces for generating the information and effectiveness in enhancing the customer relationship with these electronic spaces. It generates a conversational traffic pattern for communication. It varies from the mass media in the twentieth century including the movie, radio, television, etc. These websites provide the possibility of dialogic and conversational communication, networking and publishing in decentralized communities as well as utilizing the community effort. Furthermore, the online and fast information is among the most important advantages of these websites considered in the research by Muttanachai Suttipuna and Patricia Stantonb (Al-Khalifa \& Al-Khalifa, 2012).

The detailed information for items in store can be one of the most effective sales agents. The fast interaction and communication is considered as one of the factors influencing the creation of customers' emotional reactions, which are evidence in information transmission of clients as the information manufacturers and also can be investigated and considered in the data transfer from storage to the shop (Jones et al., 2008). Various payment methods, which are provided for customer via websites, are among other variables affecting the websites. Since the e-commerce should consider not only the information systems, but also marketing strategies, if we consider the websites with a marketing perspective in cybermarketing space, we will find that numerous cases may influence the websites or be affected by them. In a survey by Hong and Yintao (2012) on the website of Haier Group Company in China, various cases were pointed out and two cases, the optimization of providing the customer service for customers and modernization of shopping, which were suitable for research were extracted in this regard.

Modeling the application of factors influencing various websites can raise the influence by other factors called as the "Cultural Transplantation". As in the research conducted by Yusof et al. (2011) in the field of foreign languages teaching via Websites, the cultural transplantation is considered as one of the challenges in this area. Since Iran, as a country of with Islamic culture and religion, is imbued with Islamic cultures, the effective items of Islamic culture should also be considered while modeling different websites. In a study by Aliyu et al. (2012) the website features, which should be taken into account in an Islamic society in order to satisfy the customers, were numerated. The items listed in this survey included the design, content, navigation, functionality, availability, interactivity, attractiveness, and security/privacy. Furthermore, the content features included the trust, objectivity, credibility, reliability, relevance, legitimacy, and authority and most of them could be utilized by localization or taken into the great attention in Iran. Finally, it can be concluded that since every features of websites can have emotional, significant and constant impact on the customers, the website can be improved by focusing on the brand status from the customer's view and by improvement of social activities.

\subsection{Customer Loyalty}

Oliver (1999) defined the loyalty as "a deeply made commitment to re-buy or re-retain a preferred service or product consistently in the future despite the situational effects and marketing attempts with the potential to make switching behavior" (Eggert \& Ulaga, 2002). The loyalty is a most 
important research topic in the information system area (Au et al., 2008). Chang and Chen (2008) defined the e-loyalty as follows: "The concept of e-loyalty develops the traditional concept of loyalty to online consumer behavior, customer's desirable attitude toward the e-retailer who leads to repeat purchasing behavior". Finally, they defined it as the customer attitude towards the e-store, which predisposes the customer to repeat purchasing behavior. Thus, the e-loyalty is considered as a cognitive construction. Nowadays, the customer loyalty is considered as the key to business success and it is in fact one of the marketing strategies, which raise the business profitability in the long term and it leads to the firm profitability due to the customer repurchase (Yoon et al., 2013). The relationship between the loyalty and stock return, presented by Fornell et al. (2006), can be also mentioned in this regard. Understanding the market by planning and adopting appropriate strategies for making the customers loyal and enhancing their loyalty rates facilitates the achievement of longterm benefits for enterprises (Liu, 2007). Keeping the customers loyal and retaining them for not choosing the rivals are among the important bases for obtaining the profit in today's competitive world. The experience gained from cyberspace about the customers' perceptions, attitudes, and behavior in online environments is very important and also states the point that to what extent the websites can influence the initial customer choices, satisfaction and purchase intention.

\section{Methodology}

This study is accomplished through the descriptive-survey method by the help of questionnaire. In the first phase of study, the variables and key concepts are extracted through the review of areas associated with the identification process based on online shopping websites and e-marketing systems. There are 35 variables from the literature review considered, which are considered in Table 1 as follows,

\section{Table 1}

The summary of influencing factors

\begin{tabular}{|c|c|c|c|c|c|}
\hline No. & Variable & No. & Variable & No. & Variable \\
\hline 1 & Multimedia & 13 & Optimization of social activity & 25 & Reputation \\
\hline 2 & Two-way communication & 14 & Vividness of presented images & 26 & $\begin{array}{l}\text { Directing the customer thoughts and } \\
\text { responding according to their needs }\end{array}$ \\
\hline 3 & $\begin{array}{l}\text { Changing the client to the information } \\
\text { generation agent }\end{array}$ & 15 & Fast interaction and communication & 27 & Guarantee \\
\hline 4 & The possibility of using the Hypertext Structure & 16 & $\begin{array}{l}\text { Possibility of storing the disseminated data } \\
\text { and reconnecting with their }\end{array}$ & 28 & Information Authority \\
\hline 5 & $\begin{array}{l}\text { The possibility of creating the information } \\
\text { dissemination and network space in } \\
\text { decentralized communities }\end{array}$ & 17 & Performance & 29 & Availability \\
\hline 6 & Utilization of collective efforts & 18 & Aesthetics & 30 & Objectivity \\
\hline 7 & $\begin{array}{l}\text { The possibility of dialog and verbal } \\
\text { communication }\end{array}$ & 19 & Reliability & 31 & Fulfilling the information requirements \\
\hline 8 & Providing the real-time data & 20 & Storage capacity & 32 & Comparing the goods and services \\
\hline 9 & Online payment & 21 & System security and integration & 33 & Reducing the costs of searching for goods \\
\hline 10 & Service providing optimization for customers & 22 & Trust & 34 & Helping the customers to make decisions \\
\hline 11 & Sales development & 23 & Accountability & 35 & Cultural link \\
\hline 12 & Brand status from customers' views & 24 & $\begin{array}{l}\text { Receiving customized goods and service } \\
\text { distinct from others }\end{array}$ & & \\
\hline
\end{tabular}

The extracted key concepts were investigated through literature review, interviews and consultations with experts and similar and repeated cases were removed. Consequently, a primary variable list consisting of 35 key concepts, which could be considered in the questionnaire, was designed. The list of variables was reviewed and modified by researchers at several stages, thus a list of final variables of key concepts were prepared for experts. Then a list of key concepts' variables was provided for 10 experts, 10 superior experts and managers in the field of online shopping, in person and via e-mail during several stages in order to assess the content validity of questionnaire. Based on the corrective feedback and offered suggestions of group, 23 questions of primary questionnaire were reliable during several steps and the necessary changes were made in the primary questions. Consequently, a set of 23 key concepts were put on the agenda. 
In the next step, a questionnaire containing 23 questions was designed using these 23 variables. The theoretical principles of research and library studies were used in order to formulate the questions. This questionnaire was designed with the options like "completely disagree" to "completely agree" and based on the five-point Likert scale and distributed online among the studied units after determining its validity and reliability. The statistical population of this research contained the users in centers, in which those technologies were used, as well as the companies, which set up this system in Iran. At this stage, 200 questionnaires were prepared and 120 ones were answered. Therefore, the response rate to the questionnaire was $60 \%$. It seems that the response rate of $60 \%$ is a reasonable rate in this research. The questionnaire data was analyzed by SPSS software, Version 21, after distribution and collection of questionnaires and survey of responses. At the next stage of research, the internal consistency of questionnaire was assessed using Cronbach's alpha. Alpha value equal to 0.711 indicated that only about $20 \%$ of variance of total scores in the questionnaire was obtained due to the questionnaire error, thus the scale had the high reliability. According to one of the most important hypotheses of classical linear regression model, the disturbing elements have same variances. Among the numerous methods for detecting the inconsistence of variance, this study utilized Bartlett's Sphericity index for investigating the significance of information in the correlation matrix, and the chi-square value equal to 756.778 at the significance level of $(\mathrm{P}<0.001)$ indicated the existence of detectable relationship among the variables in factor analysis. To identify the variables, which explained the lower factor loadings and had a low correlation, the exploratory factor analysis was used through principal components analysis combined with the orthogonal varimax rotation; the validity of questionnaire was assessed by factor analysis and Fig. 1 and Fig. 2 represent the matrix of factors and the rotation matrix, respectively. First and before performing the factor analysis, the suitability of data was evaluated for factor analysis and then the explanatory factor analysis with the principal component analysis was conducted with varimax rotation. After performing the factor analysis, a 9-factor structure was considered.

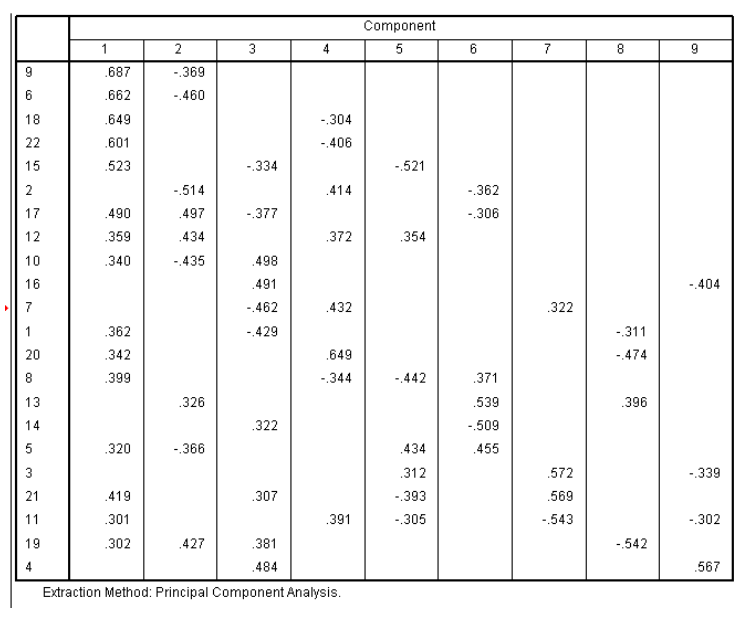

Fig. 1. Component Matrix

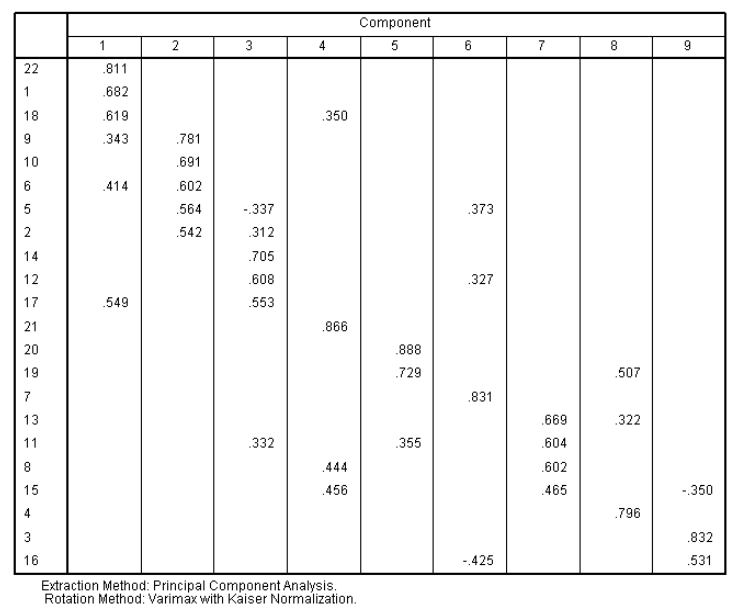

Fig. 2. Rotation Matrix

As observed, the number of factors equal to 9, which have not changed after rotation, and also these factors explain $71.465 \%$ of variance. The results of factor analysis indicated that the questionnaire had proper validity. Finally, the factors of questionnaire were named as follows through consultation with experts participating in the survey and they are summarized in Table 2. After reaching the effective components of online shopping websites, the second stage provides a structural model for the impact of these components on the customer loyalty. In this regard, a questionnaire was initially designed to evaluate the effect of constituent variables of these components on the customer loyalty, and according to the rate of these variables equal to 18, the questionnaires were distributed among 200 individuals working in this field or associated with it. Given the data obtained using AMOS software and the results are summarized in Fig. 3 and Fig 4. 
Table 2

List of components and their constituent variables

\begin{tabular}{|c|c|c|c|}
\hline Component & Component name & Variable name & Factor Weight \\
\hline \multirow{5}{*}{1} & \multirow{5}{*}{ Comprehensive information system } & Helping the customers to make decisions & 0.811 \\
\hline & & Multimedia system & 0.682 \\
\hline & & Fulfilling the information requirements & 0.619 \\
\hline & & Provid ing the real-time data & 0.414 \\
\hline & & Information Objectivity & 0.549 \\
\hline \multirow{4}{*}{2} & \multirow{4}{*}{ System Development } & Sales development & 0.781 \\
\hline & & Improvement of brand status & 0.691 \\
\hline & & Network space & 0.564 \\
\hline & & Converting the communication & 0.542 \\
\hline \multirow{3}{*}{3} & \multirow{3}{*}{ Choice power } & Ability to choose the service & 0.888 \\
\hline & & Ability to choose the goods & 0.729 \\
\hline & & Possibility of storing data & 0.355 \\
\hline \multirow{3}{*}{4} & \multirow{3}{*}{ Availability } & Reconnection with information & 0.327 \\
\hline & & Fast interaction and communication & 0.831 \\
\hline & & Availability to data & -0425 \\
\hline \multirow{3}{*}{5} & \multirow{3}{*}{ System improvement } & Improvement of performance & 0.669 \\
\hline & & Optimization of provided service for customers & 0.602 \\
\hline & & The ability to use data & 0.465 \\
\hline
\end{tabular}

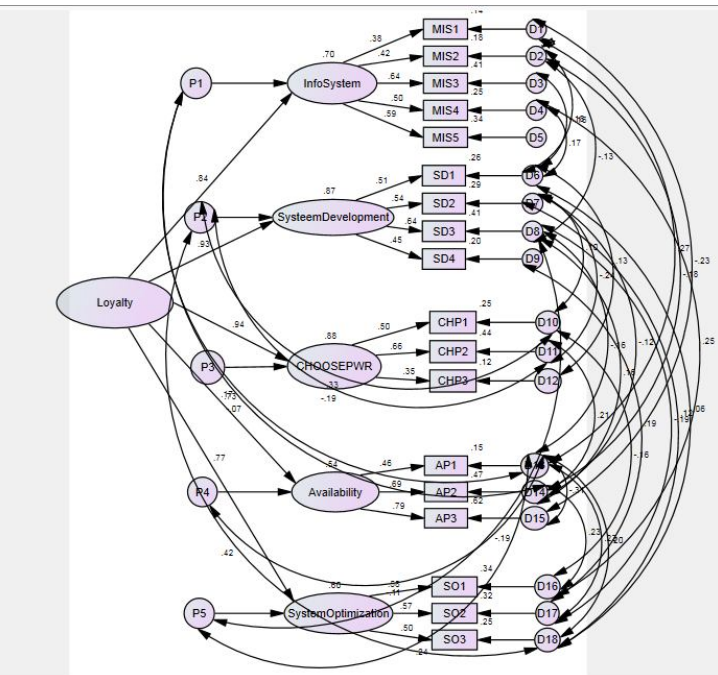

Fig. 3. Modified structural model with standardized coefficients

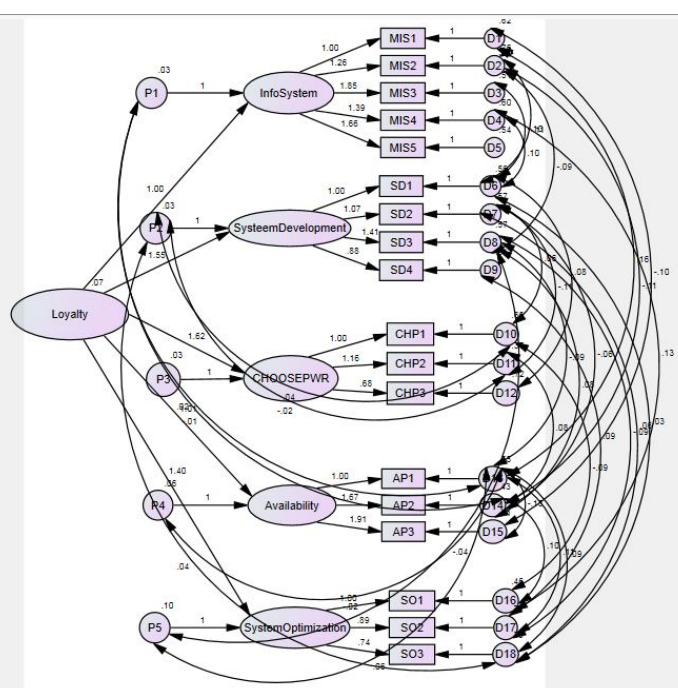

Fig. 4. Modified structural model with non-standardized coefficients

Table 3

Standardized Regression Weights: (Group number 1 - Default model)

\begin{tabular}{|c|c|c|}
\hline From & To & Estimate \\
\hline loyalty & $\rightarrow \quad$ Comprehensive information system & .836 \\
\hline loyalty & $\rightarrow \quad$ System Development & .930 \\
\hline loyalty & $\rightarrow \quad$ Choice power & .938 \\
\hline loyalty & $\rightarrow \quad$ Availability & .733 \\
\hline loyalty & $\rightarrow \quad$ System Optimization & .774 \\
\hline Comprehensive information system & $\rightarrow \quad$ Helping the customers to make decisions & .379 \\
\hline Comprehensive information system & $\rightarrow \quad$ Multimedia system & .422 \\
\hline Comprehensive information system & $\rightarrow \quad$ Fulfilling the information requirements & 640 \\
\hline Comprehensive information system & $\rightarrow \quad$ Providing the real-time data & .501 \\
\hline Comprehensive information system & $\rightarrow \quad$ Information Objectivity & .586 \\
\hline System Development & $\rightarrow \quad$ Sales Development & .512 \\
\hline System Development & $\rightarrow \quad$ Improvement of brand status & .536 \\
\hline System Development & $\rightarrow \quad$ Network space & .643 \\
\hline System Development & $\rightarrow$ Converting the communication & .451 \\
\hline Choice power & $\rightarrow \quad$ Ability to choose the service & .499 \\
\hline Choice power & $\rightarrow \quad$ Ability to choose the goods & .665 \\
\hline Choice power & $\rightarrow \quad$ Possibility of storing data & .350 \\
\hline Availability & $\rightarrow$ Reconnection with information & .460 \\
\hline Availability & $\rightarrow$ Fast interaction and communication & .686 \\
\hline Availability & $\rightarrow \quad$ Availability to data & .786 \\
\hline System Optimization & $\rightarrow$ Performance Optimization & .582 \\
\hline System Optimization & $\rightarrow$ Optimization of provided service for customers & .569 \\
\hline System Optimization & $\rightarrow \quad$ The ability to use data & .501 \\
\hline
\end{tabular}


Table 4

Squared Multiple Correlations: (Group number 1 - Default model)

\begin{tabular}{llll}
\hline Variable & Estimate & Variable & Estimate \\
\hline System Optimization & $0.6^{*}$ & Ability to choose the goods & $0.442^{*}$ \\
loyalty & $0.538^{*}$ & Possibility of storing data & $0.249^{*}$ \\
Ability to choose & $0.879^{*}$ & Converting the communication & $0.203^{*}$ \\
System Development & $0.866^{*}$ & Network space & $0.413^{*}$ \\
Comprehensive information system & $0.699^{*}$ & Improvement of brand status & $0.287^{*}$ \\
The ability to use data & $0.251^{*}$ & Sales Development & $0.263^{*}$ \\
Optimization of provided service for customers & $0.324^{*}$ & Information Objectivity & $0.343^{*}$ \\
Performance Optimization & $0.339^{*}$ & Providing the real-time data & $0.251^{*}$ \\
Availability to data & $0.617^{*}$ & Fulfilling the information requirements & $0.41^{*}$ \\
Fast interaction and communication & $0.471^{*}$ & Multimedia system & $0.178^{*}$ \\
Reconnection with information & $0.148^{*}$ & Helping the customers to make decisions & $0.144^{*}$ \\
Possibility of storing data & $0.122^{*}$ & & \\
\hline
\end{tabular}

As we can observe from the results of Table 4, all components are statistically significant. In addition, Table 5 ranks the effects of loyalty components.

Table 5

Ranking the Factors

\begin{tabular}{llc}
\hline Dependent variable & Exploratory components & Importance factor \\
\hline \multirow{4}{*}{ Loyalty } & Comprehensive information system & 0.83 \\
& System Development & 0.93 \\
& Choice power & 0.94 \\
& Availability & 0.73 \\
& System Optimization & 0.77 \\
\hline
\end{tabular}

Table 6

The summary of the effects of various factors

\begin{tabular}{|c|c|c|c|}
\hline No. & Component & Variable & Importance factor \\
\hline \multirow{5}{*}{1} & \multirow{5}{*}{ Comprehensive information system } & Helping the customers to make decisions & 0.38 \\
\hline & & Multimedia system & 0.42 \\
\hline & & Fulfilling the information requirements & 0.64 \\
\hline & & Providing the real-time data & 0.50 \\
\hline & & Information Objectivity & 0.59 \\
\hline \multirow{4}{*}{2} & \multirow{4}{*}{ System Development } & Sales Development & 0.51 \\
\hline & & Improvement of brand status & 0.53 \\
\hline & & Network space & 0.64 \\
\hline & & Converting the communication & 0.45 \\
\hline \multirow{3}{*}{3} & \multirow{3}{*}{ Choice power } & Ability to choose the service & 0.50 \\
\hline & & Ability to choose the goods & 0.66 \\
\hline & & Possibility of storing data & 0.35 \\
\hline \multirow{3}{*}{4} & \multirow{3}{*}{ Availability } & Reconnection with information & 0.46 \\
\hline & & Fast interaction and communication & 0.68 \\
\hline & & Availability to data & 0.78 \\
\hline \multirow{3}{*}{5} & \multirow{3}{*}{ System Optimization } & Performance Optimization & 0.58 \\
\hline & & Optimization of provided service for customers & 0.56 \\
\hline & & The ability to use data & 0.50 \\
\hline
\end{tabular}

\section{Discussion and Conclusion}

The results of exploratory factor analysis on the data have been summarized in the Table 6 . In our survey, out of 23 variables measured in the questionnaire, the eigenvalues of 9 factors were more than 1 and the percentage of variance shared among the variables describes 71.464 percent of the total variance of variables. In other words, the degree of accuracy expressed by these 9 factors is well 
above 71 percent. The first factor with eigenvalue of 3.545 explains about 16.112 percent of the total variance of variables.

The first hypothesis of this survey investigates whether or not the comprehensive information system component influences on the enhanced customer loyalty. Based on the statistical analysis, the net correlation coefficient for comprehensive information system component is significant with the base level of 0.83 in the field of enhanced customer loyalty. In other words, any changes in the variance of comprehensive information system component equal to 0.83 will change the variance of enhanced customer loyalty.

The second hypothesis investigates whether or not the system development component has an impact on the enhanced customer loyalty. Based on the statistical analysis, the net correlation coefficient for system development component is significant with the base level of 0.93 and $t=3.714$ in the field of enhanced customer loyalty. In other words, any changes in the variance of system development component equal to 0.93 will change the variance of enhanced customer loyalty.

The third hypothesis studies whether or not the choice power component has an impact on the enhanced customer loyalty. Based on the statistical analysis, the net correlation coefficient for Choice power component is significant with the base level of 0.94 and $t=3.523$ in the field of enhanced customer loyalty. In other words, any changes in the variance of Choice power component equal to 0.94 will change the variance of enhanced customer loyalty.

The fourth hypothesis studies whether the availability component has an impact on the enhanced customer loyalty. Based on the statistical analysis, the net correlation coefficient for Availability component is significant with the base level of 0.73 and $t=3.495$ in the field of enhanced customer loyalty. In other words, any changes in the variance of Availability component equal to 0.73 will change the variance of enhanced customer loyalty.

Finally, the last hypothesis investigates whether or not the system optimization component has an impact on the enhanced customer loyalty. Based on the statistical analysis, the net correlation coefficient for System Optimization component is significant with the base level of 0.77 and $t=3.551$ in the field of enhanced customer loyalty. In other words, any changes in the variance of System Optimization component equal to 0.99 will change the variance of enhanced customer loyalty.

We now consider the impact of online shopping websites' components on the enhanced customer loyalty. Based on the obtained results, three primary effective factors of online shopping websites on the customer loyalty are as follows based on the importance: The comprehensive information system component with 5 items, the System Development with 4 items and Choice power with 3 items. According to the cases above on the study of effective factors of online shopping websites on the enhanced customer loyalty in Iran, the comprehensive information system, with the importance factor of 0.83 , has the highest importance. In addition, the factors like the system development, with the importance factor of 0.93 , and Choice power, with the importance factor of 0.94 , come in the second and the third priorities, respectively.

Based on the obtained results, two effective factors of online shopping websites on the enhanced customer loyalty in this study are the System Optimization with 3 items and Availability with 3 items. Considering the above cases, the importance levels of the second double factors' influence on the enhanced customer loyalty are System Optimization with importance factor of 0.77 and Availability with importance factor of 0.73 . Table 7 demonstrates the results of testing sub-hypotheses. This study is an exploratory research including the components affecting the websites such as the multimedia systems design, system development, comprehensive information systems, and so on. To retain the customer loyalty, which is now one of the most important indexes of increased sales and profits, and 
since few studies are conducted in this area, we expect that this research will provide the important area for other studies. The results of study are consistent with findings reported earlier by Erdoğmuş and Cicek (2012), Rust (2001) and Nielsen (2005).

\section{Table 7}

The results of testing sub-hypotheses

\begin{tabular}{|c|c|c|c|}
\hline Subsidiary hypotheses & $\mathrm{P}$ & $\beta$ & Result \\
\hline Helving the customers to make decisions & $\mathrm{P}<0.001$ & 1.000 & Confirmed \\
\hline Multimedia system & $\mathrm{P}<0.001$ & 1.257 & Confirmed \\
\hline Fulfilling the information requirements & $\mathrm{P}<0.001$ & 1.846 & Confirmed \\
\hline Providing the real-time data & $\mathrm{P}<0.001$ & 1.391 & Confirmed \\
\hline Information Objectivity & $\mathrm{P}<0.001$ & 1.657 & Confirmed \\
\hline Sales Development & $\mathrm{P}<0.001$ & 1.000 & Confirmed \\
\hline Improvement of brand status & $\mathrm{P}<0.001$ & 1.069 & Confirmed \\
\hline Using the network space & $\mathrm{P}<0.001$ & 1.408 & Confirmed \\
\hline Converting the communication & $\mathrm{P}<0.001$ & 0.879 & Confirmed \\
\hline Ability to choose the service & $\mathrm{P}<0.001$ & 1.000 & Confirmed \\
\hline Ability to choose the goods & $\mathrm{P}<0.001$ & 1.163 & Confirmed \\
\hline Possibility of storing data & $\mathrm{P}<0.001$ & 0.678 & Confirmed \\
\hline Reconnection with information & $\mathrm{P}<0.001$ & 1.000 & Confirmed \\
\hline Fast interaction and communication & $\mathrm{P}<0.001$ & 1.666 & Confirmed \\
\hline Availability to data & $\mathrm{P}<0.001$ & 1.910 & Confirmed \\
\hline Performance Optimization & $\mathrm{P}<0.001$ & 1.000 & Confirmed \\
\hline Optimization of provided service for customers & $\mathrm{P}<0.001$ & 0.885 & Confirmed \\
\hline The ability to use data & $\mathrm{P}<0.001$ & 0.739 & Confirmed \\
\hline
\end{tabular}

\section{Acknowledgement}

The authors would like to thank the anonymous referees for constructive comments on earlier version of this paper.

\section{References}

Aliyu, M., Mahmud, M., \& Md Tap, A. O. (2012). Exploring Islamic website features that influence user satisfaction: A conceptual model. Procedia-Social and Behavioral Sciences, 65, 656-661.

Al-Khalifa, A. S., \& Al-Khalifa, H. S. (2012). Do-It-Yourself object identification using augmented reality for visually impaired people (pp. 560-565). Springer Berlin Heidelberg.

Au, N., Ngai, E. W., \& Cheng, T. E. (2008). Extending the understanding of end user information systems satisfaction formation: An equitable needs fulfillment model approach. MIS quarterly, 32(1), 43-66.

Chang, H. H., \& Chen, S. W. (2008). The impact of online store environment cues on purchase intention: Trust and perceived risk as a mediator. Online Information Review, 32(6), 818-841.

Eggert, A., \& Ulaga, W. (2002). Customer perceived value: a substitute for satisfaction in business markets?. Journal of Business \& industrial marketing,17(2/3), 107-118.

Erdoğmuş, İ. E., \& Cicek, M. (2012). The impact of social media marketing on brand loyalty. Procedia-Social and Behavioral Sciences, 58, 1353-1360.

Fornell, C., Mithas, S., Morgeson III, F. V., \& Krishnan, M. S. (2006). Customer satisfaction and stock prices: High returns, low risk. Journal of marketing,70(1), 3-14.

Hong, Z., \& Yintao, B. (2012). Analysis and Research on Haier Group's Website Construction Based on Cybermarketing-orientation. Physics Procedia,24, 1298-1303.

Jones, M. Y., Spence, M. T., \& Vallaster, C. (2008). Creating emotions via B2C websites. Business Horizons, 51(5), 419-428.

Liu, Y. (2007). The long-term impact of loyalty programs on consumer purchase behavior and loyalty. Journal of Marketing, 71(4), 19-35.

Nielsen, H. J. (2005). New media and new roles of librarianship: illustrated by a literary website of Danish libraries. New Library World, 106(11/12), 510-518.

Rust, R. T., Zeithaml, V. A., \& Lemon, K. N. (2001). Driving customer equity: How customer lifetime value is reshaping corporate strategy. Simon and Schuster. 
Yoon, V. Y., Hostler, R. E., Guo, Z., \& Guimaraes, T. (2013). Assessing the moderating effect of consumer product knowledge and online shopping experience on using recommendation agents for customer loyalty. Decision Support Systems, 55(4), 883-893.

Yusof, N. M., Aladdin, A., Lateh, N. H., Ramli, S., Yoan, R. S., \& Yusof, M. S. (2011). The Translation of Foreign Language Teaching and Learning Materials for Universiti Kebangsaan Malaysia Website: Preliminary Problems and Challenges. Procedia-Social and Behavioral Sciences, 18, 522-526.

Zalatar, W. F. (2012). Evaluating the Quality of C2C Online Buy and Sell Websites Using Dimensions of E-Quality. Procedia-Social and Behavioral Sciences, 40, 71-76. 